\title{
Angel-shaped phalango-epiphyseal dysplasia
}

INSERM

\section{Source}

INSERM. (1999). Orphanet: an online rare disease and orphan drug data base. Angelshaped phalango-epiphyseal dysplasia. ORPHA:63442

Angel-shaped phalango-epiphyseal dysplasia (ASPED) is a form of acromelic dysplasia (see this term) characterized by the distinctive radiological sign of angel-shaped middle phalanges, a typical metacarpophalangeal pattern profile (mainly affecting first metacarpals and middle phalanges of second, third and fifth digits, which all appear short), epiphyseal changes in the hips and, in some, abnormal dentition and delayed bone age. 